\title{
How can we minimise the use of regular oral corticosteroids in asthma?
}

\author{
Arnaud Bourdin ${ }^{1}$, lan Adcock ${ }^{2}$, Patrick Berger $\mathbb{1}^{3}$, Philippe Bonniaud ${ }^{4}$, \\ Philippe Chanson $\mathbb{1}^{5}$, Cécile Chenivesse ${ }^{6,7}$, Jacques de Blic ${ }^{8}$, Antoine Deschildre $\mathbb{1}^{9}$, \\ Philippe Devillier ${ }^{10}$, Gilles Devouassoux $^{11,12}$, Alain Didier ${ }^{13}$, Gilles Garcia $\mathbb{C}^{14}$, \\ Antoine Magnan ${ }^{15}$, Yan Martinat ${ }^{16}$, Thierry Perez ${ }^{17,18}$, Nicolas Roche ${ }^{19}$, \\ Camille Taillé ${ }^{20}$, Pierre Val ${ }^{21}$ and Pascal Chanez ${ }^{22}$
}

Affiliations: 'Service des Maladies Respirartoires, CHU Arnaud de Villeneuve, University of Montpellier, Montpellier, France. ${ }^{2}$ Thoracic Medicine, Imperial College London, London, UK. ${ }^{3}$ Centre de Recherche Cardiothoracique de Bordeaux, Université de Bordeaux, Bordeaux, France. ${ }^{4}$ Service de Pneumologie, $\mathrm{CHU}$ Bocage, Dijon, France. ${ }^{5}$ Endocrinology, Paris-Sud University, Orsay, France. ${ }^{6}$ Centre Hospitalier Regional Universitaire de Lille, Lille, France. "Universite de Lille II, Lille, France. ${ }^{8}$ Pediatric Respiratory Diseases, Necker-Enfants Malades Hospitals, Paris, France. ${ }^{9}$ Pediatrie, CHRU de Lille, Lille, France. ${ }^{10}$ Laboratory of Pharmacology, Hôpital Foch, Suresnes, France. ${ }^{11}$ Pneumologie, Hopital de la Croix-Rousse, HCL, Lyon, France. ${ }^{12}$ Université Claude Bernard lyon1 et INSERM U851, Lyon, France. ${ }^{13}$ Hôpital Larrey, Toulouse, France. ${ }^{14}$ Hopital Bicetre, Le Kremlin-Bicetre, France. ${ }^{15}$ Institut du Thorax, Nantes, France. ${ }^{16}$ Cabinet de Pneumologie, Lyon, France. ${ }^{17}$ Respiratory, Hopital Calmette, CHRU Lille, Lille, France. ${ }^{18}$ Lung function, Hôpital Calmette, CHRU Lille, Lille, France. ${ }^{19}$ Hopital Cochin Pneumologie, Paris, France. ${ }^{20}$ Service de Pneumologie, Hopital Bichat - Claude-Bernard, Paris, France. ${ }^{21}$ UMR 6293, Clermont Ferrand, France. ${ }^{22}$ University of Marseille, Marseille, France.

Correspondence: Arnaud Bourdin, Dept of Respiratory Diseases, Hôpital Arnaud de Villeneuve, CHU Montpellier, University of Montpellier, 371 Avenue Doyen Giraud, 34295 Montpellier, Cedex 5, France.

E-mail: a-bourdinachu-montpellier.fr

@ERSpublications

A yearly cumulative OCS dose above $1 \mathrm{~g}$ should be considered unacceptable in severe asthma and should make the case for referral http://bit.ly/34GAYLX

Cite this article as: Bourdin A, Adcock I, Berger P, et al. How can we minimise the use of regular oral corticosteroids in asthma? Eur Respir Rev 2020; 29: 190085 [https://doi.org/10.1183/16000617.0085-2019].

ABSTRACT Options to achieve oral corticosteroid (OCS)-sparing have been triggering increasing interest since the 1970s because of the side-effects of OCSs, and this has now become achievable with biologics. The Société de Pneumologie de Langue Française workshop on OCSs aimed to conduct a comprehensive review of the basics for OCS use in asthma and issue key research questions. Pharmacology and definition of regular use were reviewed by the first working group (WG1). WG2 examined whether regular OCS use is associated with T2 endotype. WG3 reported on the specificities of the paediatric area. Key "research statement proposals" were suggested by WG4. It was found that the benefits of regular OCS use in asthma outside episodes of exacerbations are poorly supported by the existing evidence. However, complete OCS elimination couldn't be achieved in any available studies for all patients and the panel felt that it was too early to conclude that regular OCS use could be declared criminal. Repeated or prolonged need for OCS beyond $1 \mathrm{~g} \cdot \mathrm{year}^{-1}$ should indicate the need for referral to secondary/tertiary care. A strategic sequential plan aiming at reducing overall exposure to OCS in severe asthma was then held as a conclusion of the workshop.

Provenance: Submitted article, peer reviewed

Received: 09 Aug 2019 | Accepted after revision: 04 Nov 2019

Copyright $\odot$ ERS 2020. This article is open access and distributed under the terms of the Creative Commons Attribution Non-Commercial Licence 4.0. 


\section{Introduction}

Since the first synthesis of corticosteroids in 1944, these drugs have largely dominated the treatment of severe asthma [1, 2]. Inhaled corticosteroids (ICSs) have been recognised as the cornerstone of asthma treatment in the context of accumulating evidence that asthma is an inflammatory disease [3-5]. The representations of both asthma and corticosteroids are highly associated in the general population, patient communities and in a broader view throughout the medical world. Oral tablets of corticosteroids (OCSs) decidedly revolutionised the management of asthma. In the late 1960s, a mere 20 years after their initial release, OCS sparing was recognised as a primary outcome in studies testing ICSs [3]. At that time, it was already emphasised that the benefit from ICSs was sometimes insufficient when a complete OCS withdrawal could not be achieved [6].

The new revolution provided by biologics now allows for challenging systemic corticosteroid use in asthma as the OCS-sparing effect is a main outcome in severe asthma management. Type 2 airway inflammation is now viewed as a key inflammatory process underlying asthma pathogenesis in a majority of patients, and this understanding was provided mostly through the identification of corticosteroid targets [7-9]. Dissection of these mechanisms led to the development of monoclonal antibodies directed against key biological processes gathered under the T2 pathway. These drugs impact on exacerbation rates and lung function in some, but not all, subjects with more severe asthma. In addition, pivotal OCS-sparing trials with these biologics were successful enough to change guidelines, where these drugs are now cited as 'preferred options' [5]. Nonetheless, surveys reveal that OCSs are still widely used as controllers in about $20 \%$ of patients with severe asthma and, most frequently, as rescue medications through repeated bursts using doses suspected to be as toxic as regular use of lower doses, and also in children with severe and nonsevere asthma [10-13]. Very few prospective and long-term longitudinal studies are available, but it was suggested that this strategy exposed patients to an increased risk of death [14-18]. Side-effects of OCSs are well known to the pulmonologist and involve virtually all organs. Interestingly, OCS-sparing strategies are developed in nearly all areas where OCSs are regularly used, not only for improving outcomes but also to address safety concerns [19-21].

Accordingly, the bold statement that "regular use of OCSs in asthma should be declared criminal" was provocatively repeated on different occasions by multiple expert clinicians experienced in the management of both adults and children with severe asthma.

\section{Methods}

As a consequence, the Asthma and Allergy Group of the Société de Pneumologie de Langue Française arranged a workshop to address this urgent question. The workshop was held in Paris, France and took place on 6 and 7 September 2018. Because a high-quality systematic review was recently released [22], it was considered futile to perform an additional systematic review, and the panel decided to concentrate its efforts on selecting key findings only. It was also decided to establish a list of key research questions and proposals ranked by the participants and weighted by the level of evidence available. The panel was comprised of experts in managing severe asthma and who were involved in OCS tapering trials with biologics, and experts in understanding pharmacology and physiology of corticosteroids and of the adrenal gland. Our working group expanded a list of statements on OCS use based on the clinical experience and expertise of the panel, current literature and the state-of-the-art presentations given by the scientists. A list of statements was first made available to all participants and those that were ranked the highest during a subsequent joint session were retained. For each statement, participants were further asked whether available evidence was of sufficient quality and were also asked to score their level of conviction/support. Evidence was graded according to the Oxford levels of evidence document [23].

\section{History of OCS in severe asthma}

The burden of OCS is the key to all definitions of severe asthma

Whereas multiple definitions of severe asthma have been proposed in adults and children, none of them is considered to be self-sufficient for the development of new drugs [5, 24-27]. It actually seems that the only convergence between academic definitions and inclusion criteria in randomised controlled trials is the burden of treatment assessed through levels of exposure to $\beta-2$ agonists and, most importantly, to ICSs and systemic corticosteroids. Beyond uncontrolled symptoms and variable airflow obstruction, the use of systemic or OCSs for $>50 \%$ of the year is the given threshold for severity in most academic definitions. Repeated OCS burst or daily OCSs despite high-dose treatment, including ICSs, are the main criteria for defining severe asthma in children. Epidemiological data showed that a significant increase in the risk of severe side-effects could appear at levels as low as 0.5 g.year ${ }^{-1}$ and became highly significant at levels $>1$ g.year $^{-1}[15,28-31]$. Most randomised controlled trials used much lower thresholds, usually set at two episodes per year requiring OCS use for $\geqslant 2$ days. In OCS-sparing trials, continuous use of OCSs at a daily dose of at least $5 \mathrm{mg}$ for $\geqslant 6$ months was considered [32-34]. Interestingly, these trials were designed very 
similarly and were based on primary outcomes nearly identical to those developed for registration studies with ICSs in the 1970s [3]. Surprisingly, in France as in other countries, OCS use is still increasing [12, 17]. Chronic airway diseases are by far the most common reason for using OCSs in the short, middle and long term [35].

Building on these shared views, a simple clinical workflow has been developed and promoted as a guidance for managing difficult-to-treat patients [5,36]. Although unspecific and encompassing many different situations, the word "difficult" mostly refers to frequent use of OCSs [37]. Ruling out alternative diagnoses and interfering comorbidities represent the two main pillars of this workflow. The third pillar, poor adherence, still challenges both patients and physicians. As poor adherence to ICSs is known to increase the risk for more frequent bursts of OCSs, it is highly likely that the burden in terms of side-effects in this population would be at least the same. In children, mechanisms of resistance to ICSs may be different according to age, with a large part of preschool severe asthma not related to allergy and/or eosinophilia [38-40]. Furthermore, severity may be related to lung function alteration, with a fixed airway obstruction or a progressive decline in forced expiratory volume in $1 \mathrm{~s}\left(\mathrm{FEV}_{1}\right)$, despite ICS daily treatment [41].

Poor corticosteroid response

The heterogeneity of asthma is inherent to its definition which is based first on airway hyperresponsiveness and secondly on an undefined chronic inflammation. Building a step-by-step classification of severity based on ICS requirements to achieve control implies that the disease is steroid-sensitive in a dose-dependent manner and becomes severe when ICSs alone fail to obtain control despite being used at their highest dosage. Whether this should be referred to as a "resistant", "insensitive", "poorly sensitive" or a "refractory" disease is a literal debate potentially misleading for non-native speakers of English. Resistant or refractory means that the disease will not benefit from corticosteroids irrespective of dose or route of administration, which is extremely paradoxical considering the OCS-based definitions of severe asthma. The ICS step-up strategy proposed through the Global Initiative for Asthma steps 2-5 in its former versions is supported by large trials such as GOAL (Gaining Optimal Asthma Control) [42], where the incremental benefit of the highest doses appeared limited. Now the Global Initiative for Asthma step-up plan (which is mostly based on existing evidence) proposes an approach based on the targeting of multiple pathways (long-acting $\beta$-agonists, long-acting muscarinic receptor antagonists, leukotriene receptor antagonists and specific immunotherapy, for example) rather than fostering the increasing dose of ICSs [43]. Maintenance and reliever therapies based on ICS-long-acting $\beta$-agonists as needed were shown to be superior to regular therapies with short-acting $\beta$-agonists on demand in reducing exacerbation rates, and this is also suggestive of a certain level of ICS dose-dependency of the underlying airway inflammation. ICSs were developed as OCS-sparing agents [3] and it is likely that some of these effects are driven by their systemic passage, given their ability to induce hypothalamic-pituitary-adrenal (HPA) axis slowing and other systemic related adverse events, such as skin bruising for instance [44].

Intuitively, the efficacy of OCSs in situations where ICSs have failed can relate to several situations: 1) ICSs are unable to reach their target because of inappropriate handling and/or an unreachable target (e.g. distal inflammation including the bone marrow and/or mucus plugging, and upper airway inflammation such as chronic rhinosinusitis with nasal polyps; 2) the target is reached but insufficiently silenced by ICSs due to molecular interferences; 3 ) the systemic part of the disease is playing a greater role than expected (e.g. when OCS-dependent asthma is the apparent feature of otherwise occult eosinophilic granulomatosis with polyangiitis (EGPA)); 4) patients have an inflammatory drive that is intrinsically relatively corticosteroid unresponsive; 5) the patients have a lesser response to ICSs than the average subject; and 6) subjects benefit from nonrespiratory effects (e.g. central nervous system effects such as pain relief or excitation) of OCSs $[45,46]$. The OCS-sparing effects of anti-interleukin (IL)-5, anti-IL-5R and anti-IL-4R do not always enable complete weaning. Aside from supplementation of a potential adrenal insufficiency, the positive benefits of OCSs over ICSs may go beyond T2 suppression via additional mechanisms (e.g. nongenomic effects) in these patients. Accordingly, a more accurate understanding of the biological effects of corticosteroids is required.

\section{Pharmacological evidence: mechanism of action and side-effects Biological evidence and mechanism of action}

The mechanism of action of steroids is actually not perfectly known $[47,48]$. This is quite surprising in view of their frequent use in the general population along with a relative perception of efficacy and safety.

Glucocorticoids (GCs) bind to the glucocorticoid receptor (GR) and the complex GC-GR will be translocated into the cell nucleus with the help of one member of the importin family [49]. The GC-GR complex will then bind to specific DNA structures and induce or repress target gene expression. 
Nongenomic effects of corticosteroids are related to direct interaction with other proteins, including transcription factors [7].

Based on the clinical response to a burst of corticosteroids (usually defined as the ability to improve $\mathrm{FEV}_{1}$ by 10-15\%) [50-52], multiple in vitro and/or ex vivo assays deciphered several biological scenarios, underlying impaired corticosteroid sensitivity, such as reduced or impaired GR expression or binding, maladapted importin7-GR interaction that can lead to decreased nuclear translocation and, more classically, reduced glucocorticoid responsive element accessibility as a consequence of histone acetyltransferases/histone deacetylases imbalance [53-56]. Among histone deacetylases down-regulators, cigarette smoking, obesity and microbial pathogens look highly relevant in the context of poor steroid sensitivity.

Other factors, such as poor absorption affecting prednisone bioavailability [57] or poor treatment adherence, may also be investigated in the context of poor steroid efficiency.

Appropriate understanding of steroid responsiveness fundamentally requires clear objective criteria, reflecting responses to these agents. This would allow for a more accurate assessment of the underlying biological processes involved. However, it is unlikely that the biological mechanisms associated with changes in lung function after a burst of systemic steroids would be exactly similar to those involved in the prevention of recurrence of exacerbations.

Finally, various models and different samples from humans showed that T2 inflammation and steroid responsiveness grossly go along each other $[9,58,59]$. IL- 4 and IL- 5 seem to be major steroid targets. In contrast, inflammatory pathways considered to be outside the borders of T2 mechanisms (e.g. T-helper cell $\left(\mathrm{T}_{\mathrm{H}}\right) 1$ and $\mathrm{T}_{\mathrm{H}} 17$ [60], and their associated pathways of Toll-like receptor, NOD, phosphatase and tensin homolog and phosphoinositide 3-kinases) have been associated with poor steroid response [61-67]. Bronchial smooth muscle cells are also poorly sensitive to corticosteroids, but this is not specific to severe asthma. Indeed, although the expressions of both $\mathrm{C}-\mathrm{EBP} \alpha$ and GR were reduced in the bronchial smooth muscle of both severe and nonsevere asthmatics, there is an impaired nuclear translocation of the GR following dexamethasone, only in severe asthmatic patients [68-72]. Similarly, fibrocytes obtained from patients with severe asthmatic appear insensitive to dexamethasone compared to those obtained from nonsevere patients with asthma or healthy controls [73, 74]. In a study of childhood difficult asthma, only $11 \%$ of 102 patients were shown to be completely corticosteroid unresponsive to a single intramuscular injection of triamcinolone, indicating that $89 \%$ of the patients had some degree of corticosteroid responsiveness [75].

In the U-BIOPRED cohort, some patients treated with systemic steroids did not have a high expression of the GR signature. It was also shown that infection-induced impairment of GR translocation to the nucleus was mostly driven by the JAK-STAT pathway [65].

Alarmins such as IL-33, thymic stromal lymphopoietin and IL-25 [76-80] are poorly steroid sensitive and targeting monoclonal antibodies is currently under development in the field of severe asthma. Whether they will modulate most of the pathways targeted by corticosteroids is also an extremely relevant question to anticipate in ICS-sensitive mild-to-moderate asthma. The alarmins pathway may be particularly relevant in children, especially in those with severe asthma prone to frequent exacerbations mainly triggered by viruses (rhinoviruses), which induce alarmins secretion by bronchial epithelial cells [81, 82].

\section{Clinical and physiological evidence}

A burst of steroids induces numerous changes in symptoms, exacerbation rate, pre- and post-bronchodilator $\mathrm{FEV}_{1}$ values, methacholine provocative dose causing a $20 \%$ fall in $\mathrm{FEV}_{1}$, sputum and blood eosinophil counts and exhaled nitric oxide fraction $\left(F_{\mathrm{eNO}}\right)$ [83]. The best responders in terms of lung function can be identified on the basis of bronchodilator reversibility, blood and sputum eosinophil counts and high $F_{\mathrm{eNO}}$ levels $[75,84]$. Features of airway remodelling, such as basement membrane thickening, which can be reverted by ICSs, were nonetheless shown as a limiting factor [85]. Bronchial vessels and airway smooth muscle layers were also shown to be reachable by corticosteroids [86, 87].

\section{OCS use among endotypes and phenotypes}

OCSs are specific to T2 airway inflammation

OCSs are mostly effective on T2 inflammation and changes in $\mathrm{FEV}_{1}$ are often used to measure their effects, assuming the link between T2 inflammation and airway hyperresponsiveness. Conversely, long-term or regular OCS bursts are now becoming a T2 surrogate marker. Potentially, a low level of remaining eosinophilic inflammation might be considered in OCS-treated patients as predicting the benefit of a T2-targeted drug; a threshold of 150 cells $\mathrm{mm}^{-3}$ in the blood has been often proposed $[32,33]$. Incidentally, this supports the assumption that eosinophils are driving the disease in such cases. Since 2009, it has been known that having a T2 signature at the epithelial level is associated with a steroid-induced FEV 1 improvement. Actually, not all T2 cytokines share similar steroid sensitivity. In addition, the microbiome, 
when oriented towards Actinobacteria [51], is likely able to decrease steroid sensitivity. Recently, the simplistic view that T2 profile and OCS sensitivity are superimposed was challenged when alarmins such as IL-33 and thymic stromal lymphopoietin, thought to belong to the T2 axis, were shown to have poor steroid sensitivity. Finally, some patients have mixed steroid sensitive/insensitive signatures (e.g. combining $\mathrm{T} 2$ and $\mathrm{T}_{\mathrm{H}} 17$ profiles).

\section{Paediatric aspects}

Use of daily OCSs in children seems unevenly distributed among a cohort of severe school and preschool-aged children with asthma among different countries, ranging from $0 \%$ to 25\% [88-90]. Follow-up in an expert centre may explain the highest frequencies, as well as recruitment before the availability of biologics. Daily doses are extremely poorly reported but tend to be similar to those seen in adults with a median of $10 \mathrm{mg}$.

Bursts of OCSs in children are likely to be more frequent than in adults. In an analysis of health plan computerised claims data, $2-5 \%$ of children with asthma received three or more bursts per year, with more in the youngest (aged 1-8 years) than in the oldest children [91]. The frequent repeated prescription of OCS bursts in preschool-aged children with asthma (<4years of age) was also shown in a Dutch study [92]. In the school-aged children with severe asthma from the U-BIOPRED cohort, the median was 3 severe exacerbations requiring OCSs in the previous year [90]. In a French cohort of 104 children with severe allergic asthma treated with omalizumab, $68 \%$ had more than two bursts of OCSs for severe exacerbations in the year before the initiation of treatment [88]. Finally, in a study comparing the efficacy of daily home spirometry to a conventional strategy, conducted during 1 year in 50 French children with severe asthma and a history of frequent severe exacerbations, a median of three severe exacerbations (interquartile range (IQR) 1-4) and a median duration of treatment with systemic corticosteroids per patient for 12 days (IQR 4.0-22.0) were observed in the conventional arm.

Expressed as number of days on OCSs, it seems that adrenal insufficiency risk begins at around 20 days per year [38, 88-90, 93, 94]. Side-effects are nonspecific but probably more carefully assessed especially the slowing of the HPA axis in the visible way that it impairs and/or delays growth. Decreased bone density or associated surrogate marker and impaired glucose tolerance are also evident in children overexposed to OCSs, not necessarily exactly parallel to reported excessive weight gain [95-101].

Accordingly, OCS-sparing or, more appropriately, OCS-preventing strategies are extremely critical in children with severe asthma. New treatment strategies with biologics reduce daily systemic corticosteroids and OCS bursts, close to zero. This has been reported in real-life omalizumab studies in a large number of children with severe allergic asthma $[93,102]$. However, these expensive drugs are not available all over the world and also not to preschool children [103]. Because low $\mathrm{FEV}_{1}$ is associated with OCS use in adults, trajectories of $\mathrm{FEV}_{1}$ are extremely meaningful for early identification of at-risk patients. Unfortunately, determinants of low $\mathrm{FEV}_{1}$ during development and childhood are poorly identified (probably similar to what is known in COPD) [104]. In a cohort of children with mild-to-moderate asthma, asthma beginning in early life, frequent exacerbations, multiple allergic sensitisations, poor environment, and high bronchial hyperresponsiveness have been associated with airway growth impairment [104]. The impact of fetal exposure to tobacco and early-life viral infections, especially lower respiratory tract infections of respiratory syncytial virus on lung function has been highlighted. Furthermore, the efficacy of ICSs and also OCSs in preschool children with asthma is lower than in older children, because of different asthma pheno-/endotypes, indicating that other early and efficient interventions are an extremely urgent unmet need [105]. Moreover, the results of the ongoing trial with omalizumab, started 2 years ago, even in mild asthmatics with a positive modified Asthma Prediction Index are eagerly awaited, as well as strategies targeting viruses (vaccines, antiviral drugs) [106]. Similarly to what is currently claimed in adults, the usefulness of referral to expert centres is demonstrated but needs better implementation for routine procedures, especially in rural areas [107-109]. Flagging the yearly consumption of OCSs should be tested as a trigger for referral. Assessing surrogate markers of asthma drivers with the aim of initiating an OCS-sparing drug also looks obvious at this age.

\section{Side-effects}

Steroid side-effects are well known. They can appear with early-life exposures and last for the patient's entire life. Oral steroids are used in asthma at very high doses compared to most other inflammatory conditions, such as rheumatoid arthritis. The different modes of administration (e.g. inhaled, systemic, transcutaneous, nebulised, intranasal) probably exert cumulative effects because even local routes are associated with some level of systemic exposure, which is rarely, if ever, taken into account. Additional effects of high-dose ICSs should be better known. Recurrent bursts may have effects differing from those of long-term daily exposure, but this remains to be further explored in real-life studies. Individual susceptibility to steroid side-effects is extremely heterogeneous [110], which supports the need for 
additional tests. These could be based on epigenetic modifications and/or pharmacogenetic findings. Costs associated with the prevention and management of steroid side-effects should be considered, while discussing the cost-effectiveness of corticosteroid-sparing strategies.

\section{Common corticosteroid side-effects}

\section{Cardiovascular}

Recognition of an increased cardiovascular risk associated with corticosteroid exposure is relatively new and, so far, this risk has not been well assessed, although given the odds ratios found in different studies, this should be considered as a primary concern [18, 28-31]. Surprisingly, in the cardiology world it is still not cited in the list of cardiovascular risk factors. It is not known whether cardiovascular effects of corticosteroids are direct or indirect (due to weight gain, diabetes and hypertension, for example) [111]. Of note, confounding factors can blur the signal in the context of systemic inflammation, myocardial eosinophilic infiltration [112-115] and combined or precipitating effects of bronchodilators (and macrolides whenever applicable [116]). Long-term follow-up of OCS-treated patients with severe asthma reported that excess mortality was mostly attributable to cardiovascular events [14, 16, 117]. Increased thickness of arterial intima/media and the left ventricle wall has been reported in asthmatics. How to achieve optimal screening for and prevention of cardiovascular complications in patients with asthma is unknown but we plea for the implementation of specific guidelines as proposed rheumatoid arthritis [118].

\section{Infection}

Pneumococcal vaccines are now recommended in patients with asthma, especially those receiving corticosteroids $[119,120]$. It is difficult to distinguish between infections related to the course of the disease and infectious adverse events attributable to corticosteroids, directly or through the occurrence of hypogammaglobulinemia or diabetes [121, 122]. Interesting debates aimed to establish whether some chronic infection with, for example, Mycoplasma, Chlamydia spp. or Pneumocystis carinii, could play a role in perpetuating asthma [123].

\section{Osteoporosis}

Corticosteroid-induced osteoporosis still merits attention in asthma as in other steroid-treated diseases [124]. In addition, ICSs have also been shown to decrease bone density and this probably represents an additional risk on top of OCSs. Odds ratios of $\sim 1.5$ were found to be associated with regular OCS use in registries and insurance claim databases $[18,30]$. Screening mostly relies on biphotonic bone absorptiometry but when it might be optimally performed remains unclear in the context of asthma. Treatment-effect modifiers may include cumulative dose (a significant increased risk was identified above $0.5 \mathrm{~g} \cdot y e a r^{-1}$, and was highly convincing above 1 g.year ${ }^{-1}$ ), duration, age, sex and other risk factors. Risk heterogeneity among subjects suggests the need to build and validate global predictive scores [110]. In children, rather than daily ICS treatment, repeated OCS bursts have been associated with osteoporosis risk, especially in boys [100, 125]. Adequate intake of calcium and vitamin D could prevent or blunt the effects on bone mineral accretion. Recently, a large case-control study reported a relationship between risk of bone fracture and bursts of systemic corticosteroids but not with ICSs in patients with asthma [126].

Metabolic syndrome and weight gain

A vicious circle probably links poorly controlled asthma, high corticosteroid exposure and obesity, even in children [101]. Interestingly, heterogeneities exist among countries and continents. A metabolic phenotype driven by IL- 6 has been identified in the Severe Asthma Research Program cohort [127]. Weight gain, diabetes and dyslipidaemia are extremely hard to control in patients receiving high doses and/or frequent bursts of OCSs [128]. Because the burden of each burst is clearly higher in patients who are obese and diabetic, the need for such bursts should be included among criteria to assess asthma severity and guide earlier therapeutic changes.

\section{Ocular}

A cataract is a well-known side-effect of corticosteroids with prevalence ranging from 1-3\% [18]. The central serous chorioretinopathy supposedly complicating systemic or topic treatments with corticosteroids is a less well-known route. This can be extremely serious, as a permanent loss of vision may result from subretinal fibrin-fibrosis with scarring of the macula. It can be improved by spironolactone. The link with corticosteroids remains very weakly evidenced as it is a rare event [129-131].

\section{Cushing syndrome and adrenal insufficiency}

Many unmet needs persist around adrenal insufficiency $[132,133]$. Adrenal glands are called "the gland of stress". They are made of two distinct tissues: 1) the central medulla derives from the neuro-ectoderm and produces catecholamines; 2 ) the cortex derives from the intermediate mesoderm and is characterised by its 
activity of steroidogenesis [134]. Progenitor cells are found within the mesenchymal capsule and are embedded in the outermost cortical zone. The cortex is divided into three distinct zones. The outer zona glomerulosa produces mineralocorticoids (aldosterone), the zona fasciculata produces GCs (cortisol) and the zona reticularis produces adrenal androgens (dihydroepiandrosterone). GC production is stimulated by adrenocorticotropic hormone (ACTH) within a well-known negative feedback loop orchestrated by the pituitary gland, in response to hypothalamic corticotropin-releasing hormone release. Both ACTH and GC releases are cyclic, with a zenith in the morning and nadir in the middle of the night.

Synthetic GCs face problematic side-effects, especially at high doses and in the long term [135]. In these situations, they lead to iatrogenic Cushing syndrome. In a manner reminiscent of primary Cushing syndrome, resulting from hyperactivity of the zona fasciculata of the adrenal cortex, iatrogenic Cushing syndrome is associated with osteoporosis, skin atrophy, diabetes, hypertension, abdominal obesity, acne, increased susceptibility to infections, stunting and high blood pressure. The deleterious psychiatric effects and bone fragility associated with Cushing syndrome can persist after normalisation of GC levels. Beyond iatrogenic Cushing syndrome [136], suppression of the HPA axis associated with chronic treatment with synthetic GCs leads to more or less pronounced adrenal insufficiency at the end of treatment. The depth of adrenal involvement depends on the dose, method of administration and duration of treatment. It may persist for $>12$ months after discontinuation of therapy. The clinical presentation of adrenal deficiency is often insidious and includes nonspecific symptoms such as fatigue, nausea, vomiting and diarrhoea, muscle weakness, weight loss and potentially hypoglycaemia. The secretion of renin-controlled aldosterone is maintained, and the onset of hyperpigmentation characteristic of Addison disease is not observed, as ACTH secretion is blunted in response to synthetic GCs. Adrenal insufficiency can lead to a potentially lethal adrenal crisis in the absence of treatment.

If inhibition of ACTH secretion can account for adrenal atrophy during the course of treatment, the persistence of insufficiency several months after its termination is difficult to explain. This may result from a failure to regain the pulsatile secretion of ACTH or a difficulty of the adrenal gland to compensate for the atrophy induced by long-term treatment. Data in a mouse model of chronic dexamethasone treatment for 14 days show that adrenals initially undergo apoptosis but have the capacity to fully regenerate over 2 weeks, by mobilising $\mathrm{SHH}^{+}$and $\mathrm{GLI}^{+}$progenitor cells in a WNT/ $\beta$-catenin dependent manner [137]. However, whether longer term treatment with GCs would result in complete inhibition of the adrenal regeneration machinery is still unclear. Interestingly though, recent data have shown that protein kinase A signalling responsiveness and $\mathrm{zF}$ differentiation are programmed by the epigenetic regulator EZH 2 through deposition of the H3K27me3 histone mark [138]. It is therefore tempting to speculate that prolonged GC exposure may alter EZH2 activity, which could result in aberrant epigenetic reprogramming of protein kinase A signalling within the adrenal and durable $\mathrm{zF}$ activity suppression.

Another puzzling aspect of adrenal insufficiency in patients receiving chronic corticosteroid therapy is the heterogeneity of response. A recent genome-wide association study has demonstrated that single nucleotide polymorphism in the platelet-dervied growth factor D locus were associated with an increased susceptibility to AI in children with asthma and adults with COPD [139]. Interestingly, deletion of both PDGF receptors $\alpha$ and $\beta$ in steroidogenic tissues results in abnormal development of the adrenal steroidogenic compartment [140]. This suggests that variants in PDGFD may have an impact on adrenal development/differentiation, which would account for variations in insufficiency in response to prolonged GC exposure. Negative impact of systemic corticosteroid on growth is clearly known [95, 141]. In contrast, the potential but small adverse effect of ICSs must be weighed against the large established benefit of these drugs to control persistent asthma [142]. It is linked to the daily dose when ICSs are prescribed at low-to-medium doses, according to the guidelines. Impact of repeated OCS bursts and daily systemic corticosteroids is far higher.

\section{Under-appreciated side-effects}

Many facets of severe asthma burden can relate directly or indirectly to GC exposure [143]. Sleep disturbance, anxiety and depression and other psychiatric/mood disorders, skin bruising, sore mouth, dental problems and weight gain; its consequence are highlighted by patients [144] and are frequently underestimated by physicians. These effects strongly impact quality of life. Fear of side-effects may induce a vicious circle related to poor adherence and poor control as well as medical nomadism [23]. In children, adverse behavioural effects of OCS bursts prescribed in asthma exacerbations have also been shown [145].

\section{A strategic step-by-step plan for globally reducing OCS exposure: a French statement}

Statements approved by the panel members of the Asthma and Allergy Group are provided in table 1. These statements were mostly driven from the strategic sequential plan held by the members of the workshop, which aimed at globally reducing and whenever possible eliminating OCSs (figure 1). 
TABLE 1 Statements assessed by the expert panel members

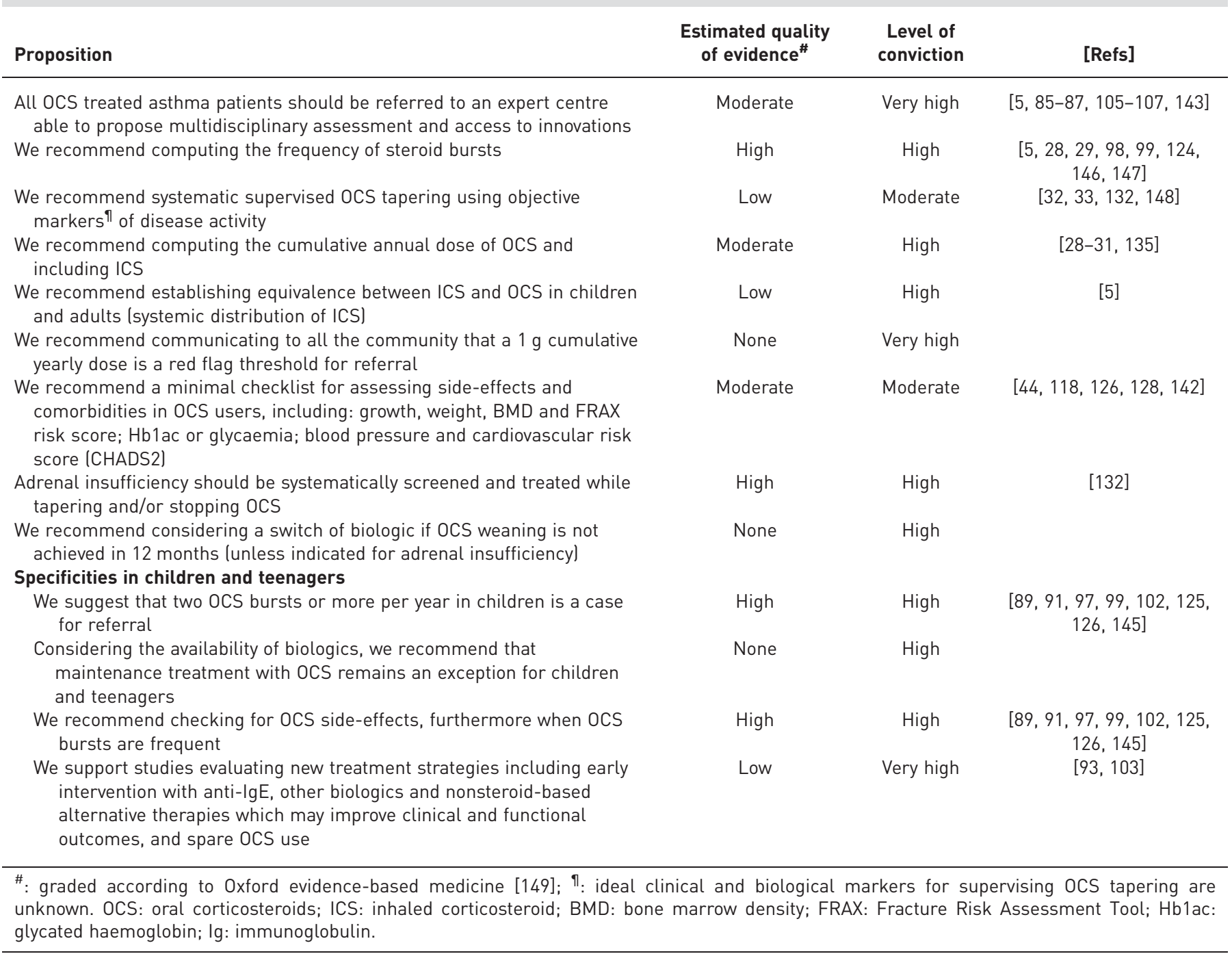

\section{Identification of patients}

OCS consumption is difficult to accurately estimate and considerable discrepancies may exist between quantities of dispensed versus actually consumed drugs. Additionally, related thresholds or "flags" for referral are not clearly identified in primary care. The concept of "asthma control" was raised nearly 40 years ago, but unfortunately was poorly integrated by patients and primary care personnel. Given this context, we felt that an opportunity existed to involve patients and pharmacists in the establishment of proposed referral thresholds, with an easy-to-recall "yellow flag" at $500 \mathrm{mg}^{-y e a r}{ }^{-1}$ for at-risk patients (obese, diabetic, osteoporotic or paediatric patients, for example) and a "red flag" at 1 g.year ${ }^{-1}$ for all patients. Personalising OCS-associated risk levels should then be proposed at this stage, for example via a specifically designed score [108].

Once identified, these patients should be assessed for a number of issues addressed in secondary care environments. OCS overuse is frequent and can substantially benefit from a multidisciplinary approach towards asthma [107]: improved adhesion to prescribed maintenance therapy, removal of a persistent exposure to known triggers (particularly allergens or pets), improving poor inhalation technique, or the discovery of untreated comorbidities. Still central and requiring multiple expertise (frequently including a psychologist/psychiatrist), OCS overuse may also result from misdiagnosis and interpretation of symptoms not necessarily caused by asthma [145]. The latter may sometimes require a justification of each OCS burst by an external adviser. For those admitted to the intensive care unit during previous tapering attempts, and those with features of specific diseases such as EGPA or allergic bronchopulmonary aspergillosis, it seems reasonable to recommend referring them to dedicated tertiary centres. 

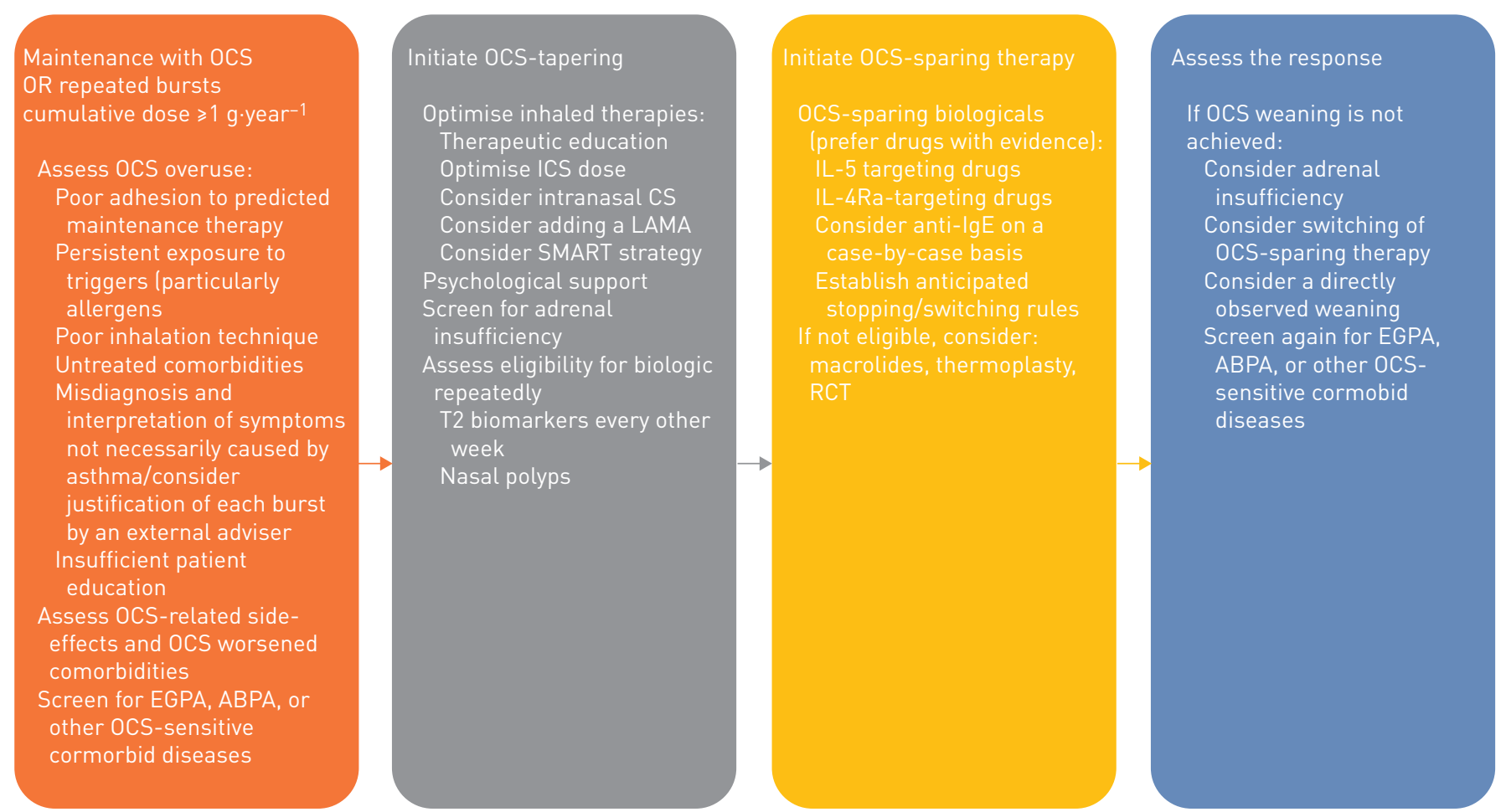

FIGURE 1 A strategic step-by-step plan for sparing oral corticosteroids (OCS) in severe asthma. EGPA: eosinophilic granulomatosis with polyangiitis; ABPA: allergic bronchopulmonary aspergillosis; ICS: inhaled corticosteroid; CS: corticosteroid; LAMA: long-acting muscarinic antagonist; IL: interleukin; Ig: immunoglobulin; RCT: randomised controlled trial. 
Initiate OCS tapering

Once the above-mentioned assessments and optimisations are successfully deployed, optimising management frequently relies on maximising the ICS dose, even though this concept may appear challenging in these patients, as discussed in the first part of this review. This may be achieved through maintenance and reliever therapy strategies. Adding another controller(s) is also recommended. Education and psychological support are key options for leveraging the chances of successful OCS weaning within a shared decision-making process. Eligibility for currently available therapeutic options can be conducted in parallel and repeated at each step of the tapering plan. We recommend systematic supervision of the OCS-tapering phase. Using objective markers of disease activity would secure the rhythm of tapering and provide key clues in the eventual reasons implicated in case of failure. Unfortunately, the "ideal" marker(s) of disease activity during an OCS-tapering phase is unknown. Whether the combination of $\mathrm{FEV}_{1}$ value, symptoms and rescue medication use will be replaced or improved by a relevant biomarker is a key question to address in the future. Since 2002, there has been evidence that use of sputum eosinophils to titrate corticosteroid dose results in better outcomes [150], suggesting the poor specificity of symptoms when considered alone. Symptoms are often due to nonasthma-related factors (i.e. obesity) and might therefore not be the best method to assess patients during OCS tapering. Beyond biological signatures associated with adrenal insufficiency, T2-related biomarkers ( $F_{\mathrm{eNO}}$, blood or sputum eosinophil counts) are OCS-sensitive in general and the maintenance of their silencing during a tapering phase should be tested.

\section{Initiate OCS-sparing therapy and assess the response}

In patients where all the previous mandatory steps could be assessed and optimally addressed, the addition of an OCS-sparing therapy is expected to not only decrease the daily maintenance dose of OCSs but also to simultaneously reduce exacerbation rates (which in itself may also further contribute to reducing overall OCS exposure [31-33]). OCS-sparing therapies may also improve certain comorbidities, frequently treated by topical or systemic corticosteroids, such as eosinophilic oesophagitis, atopic dermatitis, urticaria, nasal polyps and EGPA. Now that multiple options are available and most of the associated biomarkers are overlapping, establishing clear stopping rules at the initiation of such therapy is becoming mandatory. In light of the burdens associated with OCS use, it was estimated that OCS weaning should take first place among the goals of biological therapy. Accordingly, we considered that a 50\% decrease in OCS dose, while certainly acknowledgeable, remained an unacceptable outcome, given the risks of any maintenance OCS dose. Moreover, since multiple therapeutic options are available, we then consensually agreed that failure-to-wean justifies consideration for switching biological therapies (under the supervision of an expert as it was shown to be feasible and safe). Adrenal insufficiency and the emergence of OCS-masked associated diseases during tapering, such as EGPA or allergic bronchopulmonary aspergillosis should explain most of the clinical failures in eligible patients, except cases of addiction or the development of antidrug antibodies. The need for continuous, strict screening and management of OCS-related adverse events in these patients is recalled and emphasised.

\section{Conclusion}

At this stage, there is insufficient evidence to universally embrace the statement "Regular OCS use should be outlawed in severe asthma"; however, there is evidence that this goal is probably easier to achieve in children than in adults. Improving access to care and identification of hidden at-risk patients will probably change the landscape and improve the prognosis of severe asthma.

Acknowledgments: The authors would like to thank Elsa Darnal and Gabriel Thabut from AstraZeneca for their support and Mireille Renaud-Mallet and Carey Suehs for reviewing the language.

Conflict of interest: A. Bourdin reports institutional fees for board membership from AstraZeneca, Novartis, GSK, Boehringer Ingelheim, Chiesi, Actelion, Pfizer and Teva, outside the submitted work. I. Adcock reports grants from EU-IMI, during the conduct of the study. P. Berger reports non-financial support from AstraZeneca, during the conduct of the study; personal fees and non-financial support from AstraZeneca, Sanofi, Circassia and Menarini grants, personal fees and non-financial support from Boehringer Ingelheim, and grants and personal fees from Novartis, outside the submitted work. P. Bonniaud reports personal fees and other from Roche, Boehringer, Novartis, personal fees from TEVA and AstraZeneca, and other from Chiesi and Stallergene, outside the submitted work. P. Chanson has nothing to disclose. C. Chenivesse reports grants and personal fees from AstraZeneca and Novartis, and personal fees from AIR LIQUIDE, ALK Abello, Boehringher Ingelheim, Chiesi, GSK, Sanofi and Teva, outside the submitted work. J. de Blic reports institutional fees for board membership from GSK, Boehringer Ingelheim, AstraZeneca, Novartis, Chiesi and Stallergenes, outside the submitted work. A. Deschildre reports personal fees from Novartis, TEVA, Stallergenes Greer, AImmune, Zambon, personal fees and other from ALK, GSK, Chiesi, AstraZeneca and DBV technologies, outside the submitted work. P. Devillier reports personal fees and non-financial support from AstraZeneca and Boehringer Ingelheim, and personal fees from Chiesi, GlaxoSmithKline, Novartis and Sanofi, outside the submitted work. G. Devouassoux reports personal fees from GSK, Astra Zeneca and Novartis, during the conduct of the study. A. Didier reports institutional fees for board membership from AstraZeneca, Novartis, GSK, Boehringer Ingelheim, Chiesi and Menarini, outside the submitted work. G. Garcia reports institutional fees for board membership from AstraZeneca, Novartis, GSK, Boehringer Ingelheim, Chiesi, Actelio, Pfizer and Teva, outside the submitted work. A. Magnan has 
nothing to disclose. Y. Martinat reports institutional fees for board membership from AstraZeneca, Novartis, GSK, Boehringer Ingelheim, Chiesi, Actelio, Pfizer and Teva, outside the submitted work. T. Perez reports institutional fees for board membership from Novartis, GSK, Boehringer Ingelheim and Chiesi, grants from AstraZeneca, and fees for travel from Chiesi, AstraZeneca, and Boehringer Ingelheim, outside the submitted work. N. Roche reports grants and personal fees from Boehringer Ingelheim, Novartis and Pfizer, and personal fees from Teva, GSK, AstraZeneca, Chiesi, Mundipharma, Sanofi, Sandoz, 3M, Zambon and Trudell, outside the submitted work. C. Taillé reports personal fees, non-financial support and other from AstraZeneca and from Novartis, grants, personal fees, non-financial support and other from GSK and Sanofi, and personal fees from Teva, during the conduct of the study. P. Val has nothing to disclose. P. Chanez reports grants and personal fees from Almirall, Boehringer Ingelheim, ALK, GSK, AstraZeneca, Novartis, Teva and Chiesi, and grants from AMU, outside the submitted work.

\section{References}

$1 \quad$ Barnes PJ. Drugs for asthma. Br J Pharmacol 2006; 147: Suppl. 1, S297-S303.

2 Chu EK, Drazen JM. Asthma: one hundred years of treatment and onward. Am J Respir Crit Care Med 2005; 171: 1202-1208.

3 Cameron SJ, Cooper EJ, Crompton GK, et al. Substitution of beclomethasone aerosol for oral prednisolone in the treatment of chronic asthma. Br Med J 1973; 4: 205-207.

4 Bousquet J, Chanez P, Lacoste JY, et al. Eosinophilic inflammation in asthma. N Engl J Med 1990; 323: 1033-1039.

5 Global Initiative for Asthma (GINA). 2018 GINA Report: Global Strategy for Asthma Management and Prevention. https://ginasthma.org/2018-gina-report-global-strategy-for-asthma-management-and-prevention Date last accessed: 19 September 2018. Date last updated: 2018.

6 Herxheimer H. Should corticosteroid aerosols be used in severe chronic asthma? Thorax 1981; 36: 401-403.

7 Barnes PJ. How corticosteroids control inflammation: Quintiles Prize Lecture 2005. Br J Pharmacol 2006; 148: 245-254.

8 Bentley AM, Hamid Q, Robinson DS, et al. Prednisolone treatment in asthma. Reduction in the numbers of eosinophils, T-cells, tryptase-only positive mast cells, and modulation of IL-4, IL-5, and interferon- $\gamma$ cytokine gene expression within the bronchial mucosa. Am J Respir Crit Care Med 1996; 153: 551-556.

9 Woodruff PG, Modrek B, Choy DF, et al. T-helper type 2-driven inflammation defines major subphenotypes of asthma. Am J Respir Crit Care Med 2009; 180: 388-395.

10 Rabe KF, Vermeire PA, Soriano JB, et al. Clinical management of asthma in 1999: the Asthma Insights and Reality in Europe (AIRE) study. Eur Respir J 2000; 16: 802-807.

11 Demoly P, Annunziata K, Gubba E, et al. Repeated cross-sectional survey of patient-reported asthma control in Europe in the past 5 years. Eur Respir Rev 2012; 21: 66-74.

12 Bourdin A, Fabry-Vendrand C, Ostinelli J, et al. The burden of severe asthma in France: a case-control study using a medical claims database. J Allergy Clin Immunol Pract 2019; 7: 1477-1487.

13 Normansell R, Kew KM, Mansour G. Different oral corticosteroid regimens for acute asthma. Cochrane Database Syst Rev 2016: 5: CD011801.

14 Bourdin A, Molinari N, Vachier I, et al. Mortality: a neglected outcome in OCS-treated severe asthma. Eur Respir J 2017; 50: 1701486.

15 Voorham J, Xu X, Price DB, et al. Healthcare resource utilization and costs associated with incremental systemic corticosteroid exposure in asthma. Allergy 2019; 74: 273-283.

16 Royal College of Physicians of London. Why asthma still kills: the national review of asthma deaths (NRAD). Confidential enquiry report. London, RCP, 2014.

17 Belhassen M, Nolin M, Nibber A, et al. Changes in persistent asthma care and outcomes from 2006 to 2016 in France. J Allergy Clin Immunol Pract 2019; 7: 1858-1867.

18 Barry LE, O'Neill C, Patterson C, et al. Age and sex associations with systemic corticosteroid-induced morbidity in asthma. J Allergy Clin Immunol Pract 2018; 6: 2014-2023.

19 Kaul A, Gordon C, Crow MK, et al. Systemic lupus erythematosus. Nat Rev Dis Primer 2016; 2: 16039.

20 Townsend HB, Saag KG. Glucocorticoid use in rheumatoid arthritis: benefits, mechanisms, and risks. Clin Exp Rheumatol 2004; 22: S77-S82.

21 Jacobs JWG, Bijlsma JWJ. Glucocorticoids in rheumatoid arthritis: lessons from the Utrecht study. Clin Exp Rheumatol 2011; 29: S59-S62.

22 Volmer T, Effenberger T, Trautner C, et al. Consequences of long-term OCS therapy and its side effects in severe asthma in adults: a focused review of the impact data in the literature. Eur Respir J 2018; 52: 1800703.

23 Menzies-Gow A, Canonica G-W, Winders TA, et al. A charter to improve patient care in severe asthma. Adv Ther 2018; 35: 1485-1496.

24 Chung KF, Wenzel SE, Brozek JL, et al. International ERS/ATS guidelines on definition, evaluation and treatment of severe asthma. Eur Respir J 2014; 43: 343-373.

25 Bel EH, Sousa A, Fleming L, et al. Diagnosis and definition of severe refractory asthma: an international consensus statement from the Innovative Medicine Initiative (IMI). Thorax 2011; 66: 910-917.

26 Bousquet J, Mantzouranis E, Cruz AA, et al. Uniform definition of asthma severity, control, and exacerbations: document presented for the World Health Organization consultation on severe asthma. J Allergy Clin Immunol 2010; 126: 926-938.

27 Proceedings of the ATS workshop on refractory asthma: current understanding, recommendations, and unanswered questions. American Thoracic Society. Am J Respir Crit Care Med 2000; 162: 2341-2351.

28 Sweeney J, Patterson CC, Menzies-Gow A, et al. Comorbidity in severe asthma requiring systemic corticosteroid therapy: cross-sectional data from the Optimum Patient Care Research Database and the British Thoracic Difficult Asthma Registry. Thorax 2016; 71: 339-346.

29 Price DB, Trudo F, Voorham J, et al. Adverse outcomes from initiation of systemic corticosteroids for asthma: long-term observational study. J Asthma Allergy 2018; 11: 193-204.

30 Lefebvre P, Duh MS, Lafeuille M-H, et al. Acute and chronic systemic corticosteroid-related complications in patients with severe asthma. J Allergy Clin Immunol 2015; 136: 1488-1495. 
Dalal AA, Duh MS, Gozalo L, et al. Dose-response relationship between long-term systemic corticosteroid use and related complications in patients with severe asthma. J Manag Care Spec Pharm 2016; 22: 833-847.

Nair P, Wenzel S, Rabe KF, et al. Oral glucocorticoid-sparing effect of benralizumab in severe asthma. $N$ Engl $J$ Med 2017; 376: 2448-2458.

Bel EH, Wenzel SE, Thompson PJ, et al. Oral glucocorticoid-sparing effect of mepolizumab in eosinophilic asthma. N Engl J Med 2014; 371: 1189-1197.

Rabe KF, Nair P, Brusselle G, et al. Efficacy and safety of dupilumab in glucocorticoid-dependent severe asthma. N Engl J Med 2018; 378: 2475-2485.

Bénard-Laribière A, Pariente A, Pambrun E, et al. Prevalence and prescription patterns of oral glucocorticoids in adults: a retrospective cross-sectional and cohort analysis in France. BMJ Open 2017; 7: e015905.

Chanez P, Wenzel SE, Anderson GP, et al. Severe asthma in adults: what are the important questions? J Allergy Clin Immunol 2007; 119: 1337-1348.

Chung KF, Godard P, Adelroth E, et al. Difficult/therapy-resistant asthma: the need for an integrated approach to define clinical phenotypes, evaluate risk factors, understand pathophysiology and find novel therapies. ERS Task Force on Difficult/Therapy-Resistant Asthma. European Respiratory Society. Eur Respir J 1999; 13: 1198-1208.

Bossley CJ, Saglani S, Kavanagh C, et al. Corticosteroid responsiveness and clinical characteristics in childhood difficult asthma. Eur Respir J 2009; 34: 1052-1059.

Bossley CJ, Fleming L, Gupta A, et al. Pediatric severe asthma is characterized by eosinophilia and remodeling without TH2 cytokines. J Allergy Clin Immunol 2012; 129: 974-982.

Nagakumar P, Puttur F, Gregory LG, et al. Pulmonary type-2 innate lymphoid cells in paediatric severe asthma: phenotype and response to steroids. Eur Respir J 2019; 54: 1801809.

Tillie-Leblond I, de Blic J, Jaubert F, et al. Airway remodeling is correlated with obstruction in children with severe asthma. Allergy 2008; 63: 533-541.

Bateman ED, Boushey HA, Bousquet J, et al. Can guideline-defined asthma control be achieved? The Gaining Optimal Asthma ControL study. Am J Respir Crit Care Med 2004; 170: 836-844.

Global Initiative for Asthma (GINA). Global Strategy for Asthma Management and Prevention. 2019. Date last accessed: June 2019. Date last updated: September 2019. https://ginasthma.org.

Malo J, Cartier A, Ghezzo H, et al. Skin bruising, adrenal function and markers of bone metabolism in asthmatics using inhaled beclomethasone and fluticasone. Eur Respir J 1999; 13: 993-998.

Pavord ID, Brightling CE, Woltmann G, et al. Non-eosinophilic corticosteroid unresponsive asthma. Lancet 1999; 353: 2213-2214.

Bush A, Kleinert S, Pavord ID. The asthmas in 2015 and beyond: a Lancet Commission. Lancet 2015; 385: 1273-1275.

Rhen T, Cidlowski JA. Anti-inflammatory action of glucocorticoids - new mechanisms for old drugs. $N$ Engl Med 2005; 353: 1711-1723.

Vandewalle J, Luypaert A, De Bosscher K, et al. Therapeutic mechanisms of glucocorticoids. Trends Endocrinol Metab 2018; 29: 42-54.

Hakim A, Barnes PJ, Adcock IM, et al. Importin-7 mediates glucocorticoid receptor nuclear import and is impaired by oxidative stress, leading to glucocorticoid insensitivity. FASEB J 2013; 27: 4510-4519.

Carmichael J, Paterson IC, Diaz P, et al. Corticosteroid resistance in chronic asthma. Br Med J (Clin Res Ed) 1981; 282: 1419-1422.

Goleva E, Jackson LP, Harris JK, et al. The effects of airway microbiome on corticosteroid responsiveness in asthma. Am J Respir Crit Care Med 2013; 188: 1193-1201.

Barnes PJ, Adcock IM. Transcription factors and asthma. Eur Respir J 1998; 12: 221-234.

Adcock IM, Chou P-C,

Adcock IM, Mumby S. Glucocorticoids. Handb Exp Pharmacol 2017; 237: 171-196.

Barnes PJ, Adcock IM. Glucocorticoid resistance in inflammatory diseases. Lancet 2009; 373: 1905-1917.

Barnes PJ, Adcock IM, Ito K. Histone acetylation and deacetylation: importance in inflammatory lung diseases. Eur Respir J 2005; 25: 552-563.

Garg V, Jusko WJ. Bioavailability and reversible metabolism of prednisone and prednisolone in man. Biopharm Drug Dispos 1994; 15: 163-172.

Cowan DC, Taylor DR, Peterson LE, et al. Biomarker-based asthma phenotypes of corticosteroid response. J Allergy Clin Immunol 2015; 135: 877-883.

Dunican EM, Fahy JV. Asthma and corticosteroids: time for a more precise approach to treatment. Eur Respir J 2017; 49: 1701167.

Chambers ES, Nanzer AM, Pfeffer PE, et al. Distinct endotypes of steroid-resistant asthma characterized by IL-17A(high) and IFN- $\gamma$ (high) immunophenotypes: potential benefits of calcitriol. J Allergy Clin Immunol 2015 136: 628-637.

Swedin L, Saarne T, Rehnberg M, et al. Patient stratification and the unmet need in asthma. Pharmacol Ther 2017; 169: 13-34

Moore WC, Meyers DA, Wenzel SE, et al. Identification of asthma phenotypes using cluster analysis in the Severe Asthma Research Program. Am I Respir Crit Care Med 2010; 181: 315-323.

Haldar P, Pavord ID, Shaw DE, et al. Cluster analysis and clinical asthma phenotypes. Am J Respir Crit Care Med 2008; 178: 218-224.

Moore WC, Hastie AT, Li X, et al. Sputum neutrophil counts are associated with more severe asthma phenotypes using cluster analysis. J Allergy Clin Immunol 2014; 133: 1557-1563.

Loza MJ, Djukanovic R, Chung KF, et al. Validated and longitudinally stable asthma phenotypes based on cluster analysis of the ADEPT study. Respir Res 2016; 17: 165.

Brusselle GG, Maes T, Bracke KR. Eosinophils in the spotlight: eosinophilic airway inflammation in nonallergic asthma. Nat Med 2013; 19: 977-979.

Carr TF, Zeki AA, Kraft M. Eosinophilic and non-eosinophilic asthma. Am J Respir Crit Care Med 2018; 197 $22-37$. 
Trian T, Benard G, Begueret $\mathrm{H}$, et al. Bronchial smooth muscle remodeling involves calcium-dependent enhanced mitochondrial biogenesis in asthma. I Exp Med 2007; 204: 3173-3181.

Johnson PR, Roth M, Tamm M, et al. Airway smooth muscle cell proliferation is increased in asthma. Am J Respir Crit Care Med 2001; 164: 474-477.

Roth M, Johnson PRA, Borger P, et al. Dysfunctional interaction of $\mathrm{C} / \mathrm{EBP} \alpha$ and the glucocorticoid receptor in asthmatic bronchial smooth-muscle cells. N Engl J Med 2004; 351: 560-574.

Chang P-J, Michaeloudes C, Zhu J, et al. Impaired nuclear translocation of the glucocorticoid receptor in corticosteroid-insensitive airway smooth muscle in severe asthma. Am J Respir Crit Care Med 2015; 191: 54-62.

Girodet P-O, Dournes G, Thumerel M, et al. Calcium channel blocker reduces airway remodeling in severe asthma. A proof-of-concept study. Am J Respir Crit Care Med 2015; 191: 876-883.

Bara I, Ozier A, de Lara J-M T, et al. Pathophysiology of bronchial smooth muscle remodelling in asthma. Eur Respir J 2010; 36: 1174-1184.

Lo C-Y, Michaeloudes C, Bhavsar PK, et al. Increased phenotypic differentiation and reduced corticosteroid sensitivity of fibrocytes in severe asthma. J Allergy Clin Immunol 2015; 135: 1186-1195.

Phipatanakul W, Mauger DT, Sorkness RL, et al. Effects of age and disease severity on systemic corticosteroid responses in asthma. Am J Respir Crit Care Med 2017; 195: 1439-1448.

Bartemes KR, Kita H. Dynamic role of epithelium-derived cytokines in asthma. Clin Immunol Orlando Fla 2012; 143: $222-235$

Cheng D, Xue Z, Yi L, et al. Epithelial interleukin-25 is a key mediator in Th2-high, corticosteroid-responsive asthma. Am J Respir Crit Care Med 2014; 190: 639-648.

Gauvreau GM, O'Byrne PM, Boulet L-P, et al. Effects of an anti-TSLP antibody on allergen-induced asthmatic responses. N Engl J Med 2014; 370: 2102-2110.

Liu S, Verma M, Michalec L, et al. Steroid resistance of airway type 2 innate lymphoid cells from patients with severe asthma: the role of thymic stromal lymphopoietin. J Allergy Clin Immunol 2018; 141: 257-268. e6.

Saglani S, Lui S, Ullmann N, et al. IL-33 promotes airway remodeling in pediatric patients with severe steroid-resistant asthma. J Allergy Clin Immunol 2013; 132: 676-685.

Deschildre A, Pichavant M, Engelmann I, et al. Virus-triggered exacerbation in allergic asthmatic children: neutrophilic airway inflammation and alteration of virus sensors characterize a subgroup of patients. Respir Res 2017; 18: 191

Jurak LM, Xi Y, Landgraf M, et al. Interleukin 33 selectively augments rhinovirus-induced type 2 immune responses in asthmatic but not healthy people. Front Immunol 2018; 9: 1895.

Wu W, Bang S, Bleecker ER, et al. Multiview cluster analysis identifies variable corticosteroid response phenotypes in severe asthma. Am J Respir Crit Care Med 2019; 199: 1358-1367.

Berthon BS, Gibson PG, Wood LG, et al. A sputum gene expression signature predicts oral corticosteroid response in asthma. Eur Respir J 2017; 49: 1700180.

Bourdin A, Kleis S, Chakra M, et al. Limited short-term steroid responsiveness is associated with thickening of bronchial basement membrane in severe asthma. Chest 2012; 141: 1504-1511.

Trigg CJ, Manolitsas ND, Wang J, et al. Placebo-controlled immunopathologic study of four months of inhaled corticosteroids in asthma. Am J Respir Crit Care Med 1994; 150: 17-22.

Chetta A, Zanini A, Foresi A, et al. Vascular component of airway remodeling in asthma is reduced by high dose of fluticasone. Am J Respir Crit Care Med 2003; 167: 751-757.

Deschildre A, Marguet C, Salleron J, et al. Add-on omalizumab in children with severe allergic asthma: a 1-year real life survey. Eur Respir J 2013; 42: 1224-1233.

Fitzpatrick AM. Severe asthma in children: lessons learned and future directions. J Allergy Clin Immunol Pract 2016; 4: 11-19.

Fleming L, Murray C, Bansal AT, et al. The burden of severe asthma in childhood and adolescence: results from the paediatric U-BIOPRED cohorts. Eur Respir J 2015; 46: 1322-1333.

Farber HJ, Silveira EA, Vicere DR, et al. Oral corticosteroid prescribing for children with asthma in a Medicaid managed care program. Pediatrics 2017; 139: e20164146.

khazaeli A, Vijverberg SJH, van der Ent CK, et al. High incidence of oral corticosteroids prescriptions in children with asthma in early childhood. J Asthma 2016; 53: 1012-1017.

Deschildre A, Marguet C, Langlois C, et al. Real-life long-term omalizumab therapy in children with severe allergic asthma. Eur Respir J 2015; 46: 856-859.

Bossley CJ, Fleming L, Ullmann N, et al. Assessment of corticosteroid response in pediatric patients with severe asthma by using a multidomain approach. J Allergy Clin Immunol 2016; 138: 413-420.

Aljebab F, Alanazi M, Choonara I, et al. Observational study on the palatability and tolerability of oral prednisolone and oral dexamethasone in children in Saudi Arabia and the UK. Arch Dis Child 2018; 103: 83-88.

Aljebab F, Alanazi M, Choonara I, et al. Tolerability of prednisolone and dexamethasone in children in Saudi Arabia. Arch Dis Child 2016; 101: e2.

Fernandes RM, Oleszczuk M, Woods CR, et al. The Cochrane library and safety of systemic corticosteroids for acute respiratory conditions in children: an overview of reviews. Evid-Based Child Health Cochrane Rev J 2014; 9: 733-747.

Ducharme FM, Chabot G, Polychronakos C, et al. Safety profile of frequent short courses of oral glucocorticoids in acute pediatric asthma: impact on bone metabolism, bone density, and adrenal function. Pediatrics 2003; 111: 376-383.

Dolan LM, Kesarwala HH, Holroyde JC, et al. Short-term, high-dose, systemic steroids in children with asthma: the effect on the hypothalamic-pituitary-adrenal axis. J Allergy Clin Immunol 1987; 80: 81-87.

Kelly HW, Van Natta ML, Covar RA, et al. Effect of long-term corticosteroid use on bone mineral density in children: a prospective longitudinal assessment in the Childhood Asthma Management Program (CAMP) study. Pediatrics 2008; 122: e53-e61.

01 Forno E, Lescher R, Strunk R, et al. Decreased response to inhaled steroids in overweight and obese asthmatic children. J Allergy Clin Immunol 2011; 127: 741-749.

Brodlie M, McKean MC, Moss S, et al. The oral corticosteroid-sparing effect of omalizumab in children with severe asthma. Arch Dis Child 2012; 97: 604-609. 


\section{disorders:} 106-131. 169-179.

Papadopoulos NG, Čustović A, Cabana MD, et al. Pediatric asthma: an unmet need for more effective, focused treatments. Pediatr Allergy Immunol 2019; 30: 7-16.

McGeachie MJ, Yates KP, Zhou X, et al. Patterns of growth and decline in lung function in persistent childhood asthma. N Engl J Med 2016; 374: 1842-1852.

Ducharme FM, Tse SM, Chauhan B. Diagnosis, management, and prognosis of preschool wheeze. Lancet 2014; 383: $1593-1604$.

Potaczek DP, Unger SD, Zhang N, et al. Development and characterization of DNAzyme candidates demonstrating significant efficiency against human rhinoviruses. J Allergy Clin Immunol 2019; 143: 1403-1415.

Porsbjerg C, Ulrik C, Skjold T, et al. Nordic consensus statement on the systematic assessment and management of possible severe asthma in adults. Eur Clin Respir J 2018; 5: 1440868.

Patil VK, Townshend C, Mitchell F, et al. An outreaching model of tertiary difficult asthma care reduces adverse asthma outcomes and healthcare utilisation costs. Eur Respir J 2016; 47: 1857-1860.

van der Meer A-N, Pasma H, Kempenaar-Okkema W, et al. A 1-day visit in a severe asthma centre: effect on asthma control, quality of life and healthcare use. Eur Respir J 2016; 48: 726-733.

Miloslavsky EM, Naden RP, Bijlsma JWJ, et al. Development of a glucocorticoid toxicity index (GTI) using multicriteria decision analysis. Ann Rheum Dis 2017; 76: 543-546. disease, and heart failure: a prospective study of 2 matched cohorts. Am J Epidemiol 2012; 176: 1014-1024. inflammatory cytokines, IL-6 and TNF $\alpha$, in peripheral blood. Inflammation 2017; 40: 1225-1235.

Sneeboer MMS, Majoor CJ, de Kievit A, et al. Prothrombotic state in patients with severe and prednisolone-dependent asthma. J Allergy Clin Immunol 2016; 137: 1727-1732.

Tattersall MC, Barnet JH, Korcarz CE, et al. Late-onset asthma predicts cardiovascular disease events: the Wisconsin sleep cohort. J Am Heart Assoc 2016; 5: e003448.

Tattersall MC, Guo M, Korcarz CE, et al. Asthma predicts cardiovascular disease events: the multi-ethnic study of atherosclerosis. Arterioscler Thromb Vasc Biol 2015; 35: 1520-1525.

Periti P, Mazzei T, Mini E, et al. Pharmacokinetic drug interactions of macrolides. Clin Pharmacokinet 1992; 23:

Abramson MJ, Bailey MJ, Couper FJ, et al. Are asthma medications and management related to deaths from asthma? Am J Respir Crit Care Med 2001; 163: 12-18.

Barber CEH, Smith A, Esdaile JM, et al. Best practices for cardiovascular disease prevention in rheumatoid arthritis: a systematic review of guideline recommendations and quality indicators. Arthritis Care Res 2015; 67:

Weycker D, Farkouh RA, Strutton DR, et al. Rates and costs of invasive pneumococcal disease and pneumonia in persons with underlying medical conditions. BMC Health Serv Res 2016; 16: 182.

Talbot TR, Hartert TV, Mitchel E, et al. Asthma as a risk factor for invasive pneumococcal disease. N Engl J Med 2005; 352: 2082-2090.

Youssef J, Novosad SA, Winthrop KL. Infection risk and safety of corticosteroid use. Rheum Dis Clin North Am 2016; 42: 157-176.

Dupin C, Marchand-Adam S, Favelle O, et al. Asthma and hypogammaglobulinemia: an asthma phenotype with low type 2 inflammation. J Clin Immunol 2016; 36: 810-817.

Eddens T, Campfield BT, Serody K, et al. A novel CD4 $4^{+}$T-cell-dependent murine model of pneumocystis-driven asthma-like pathology. Am J Respir Crit Care Med 2016; 194: 807-820.

Buehring B, Viswanathan R, Binkley N, et al. Glucocorticoid-induced osteoporosis: an update on effects and management. J Allergy Clin Immunol 2013; 132: 1019-1030.

Lancet Respir Med 2014; 2: 487-496.

Gray N, Howard A, Zhu J, et al. Association between inhaled corticosteroid use and bone fracture in children with asthma. JAMA Pediatr 2018; 172: 57-64. asthma severity: a cross-sectional analysis of two cohorts. Lancet Respir Med 2016; 4: 574-584.

Bonaventura A, Montecucco F. Steroid-induced hyperglycemia: an underdiagnosed problem or clinical inertia? A narrative review. Diabetes Res Clin Pract 2018; 139: 203-220.

Liu B, Deng T, Zhang J. Risk factors for central serous chorioretinopathy: a systematic review and meta-analysis. Retina Phila Pa 2016; 36: 9-19.

Nicholson BP, Atchison E, Idris AA, et al. Central serous chorioretinopathy and glucocorticoids: an update on evidence for association. Surv Ophthalmol 2018; 63: 1-8.

Ricketti PA, Unkle DW, Cleri DJ, et al. Central serous chorioretinopathy secondary to corticosteroids in patients with atopic disease. Allergy Asthma Proc 2015; 36: 123-129.

Broersen LHA, Pereira AM, Jørgensen JOL, et al. Adrenal insufficiency in corticosteroids use: systematic review and meta-analysis. J Clin Endocrinol Metab 2015; 100: 2171-2180.

ayman E, Drake AJ. Adrenal suppression with glucocorticoid therapy: still a problem after all these years? Arch Dis Child 2017; 102: 338-339.

Paragliola RM, Papi G, Pontecorvi A, et al. Treatment with synthetic glucocorticoids and the hypothalamuspituitary-adrenal axis. Int J Mol Sci 2017; 18: E2201.

Webb SM, Valassi E. Morbidity of Cushing's syndrome and impact of treatment. Endocrinol Metab Clin North Am 2018; 47: 299-311.

Finco I, Lerario AM, Hammer GD. Sonic hedgehog and WNT signaling promote adrenal gland regeneration in male mice. Endocrinology 2018; 159: 579-596.

Mathieu M, Drelon C, Rodriguez S, et al. Steroidogenic differentiation and PKA signaling are programmed by histone methyltransferase EZH2 in the adrenal cortex. Proc Natl Acad Sci USA 2018; 115: E12265-E12274. 
Hawcutt DB, Francis B, Carr DF, et al. Susceptibility to corticosteroid-induced adrenal suppression: a genome-wide association study. Lancet Respir Med 2018; 6: 442-450.

140 Schmahl J, Rizzolo K, Soriano P. The PDGF signaling pathway controls multiple steroid-producing lineages. Genes Dev 2008; 22: 3255-3267.

141 Kamada AK, Szefler SJ. Glucocorticoids and growth in asthmatic children. Pediatr Allergy Immunol 1995; 6: $145-154$.

142 Pruteanu AI, Chauhan BF, Zhang L, et al. Inhaled corticosteroids in children with persistent asthma: dose-response effects on growth. Cochrane Database Syst Rev 2014; 7: CD009878.

143 Foster JM, McDonald VM, Guo M, et al. "I have lost in every facet of my life": the hidden burden of severe asthma. Eur Respir J 2017; 50: 1700765.

144 Hyland ME, Jones RC, Lanario JW, et al. The construction and validation of the Severe Asthma Questionnaire Eur Respir J 2018; 52: 1800618.

145 Kayani S, Shannon DC. Adverse behavioral effects of treatment for acute exacerbation of asthma in children: a comparison of two doses of oral steroids. Chest 2002; 122: 624-628.

146 Haldar P, Brightling CE, Hargadon B, et al. Mepolizumab and exacerbations of refractory eosinophilic asthma. $N$ Engl J Med 2009; 360: 973-984.

147 Bleecker ER, FitzGerald JM, Chanez P, et al. Efficacy and safety of benralizumab for patients with severe asthma uncontrolled with high-dosage inhaled corticosteroids and long-acting $\beta 2$-agonists (SIROCCO): a randomised, multicentre, placebo-controlled phase 3 trial. Lancet 2016; 388: 2115-2127.

148 Nicolaides NC, Pavlaki AN, Maria Alexandra MA, et al. Glucocorticoid therapy and adrenal suppression. In: Feingold KR, Anawalt B, Boyce A, et al., eds. Endotext. South Dartmouth, MDText.com, Inc., 2000.

149 CEBM. OCEBM Levels of Evidence. www.cebm.net/2016/05/ocebm-levels-of-evidence Date last accessed: 17 September 2019. Date last updated: May 2016.

150 Green RH, Brightling CE, McKenna S, et al. Asthma exacerbations and sputum eosinophil counts: a randomised controlled trial. Lancet 2002; 360: 1715-1721. 